\title{
Arazi Kullanımlarının Sınıflandırılmasında Piksel ve Obje Tabanlı Sınıflandırmanın Karșılaștırılması
}

\section{DERYA GÜLÇÍN'(i⿺}

\author{
' Aydın Adnan Menderes Üniversitesi Ziraat Fakültesi Peyzaj Mimarlığı Bölümü, Aydın
}

Öz: Yüksek çözünürlüklü uydu görüntülerinin sınıflandırılmasıyla olușturulan arazi örtüsü-arazi kullanımı (AÖ/AK) envanterleri, hem kent ölçeğinde hem de peyzaj ölçeğindeki planlama uygulamalarının yürütülmesi açısından önem tașımaktadır. Avrupa'da alan kullanım planlaması kapsamında hazırlanan kent atlasları, peyzaj ölçeğindeki Natura 2000 ve CORINE veri setlerine dayanan haritalar, uydu görüntülerinin yüksek doğrulukla sınıflandırılması ile olușturulmaktadır. Sınıflandırma tekniklerinden kontrollü ve kontrolsüz sınıflandırmanın yanı sıra, güncel bir yöntem olan obje tabanlı sınıflama da etkin olarak kullanılmaktadır. Bu çalıșmanın materyali olarak, 2013 yılına ait Aydın kentsel yerleșim merkezi sınıındaki 0.5 m yersel çözünürlüğe sahip Worldview Ortoready Pansharpened uydu görüntüsü ve görüntünün yorumlanmasında Google Earth Pro yazılımının geçmiș görüntüleri arasında aynı yılı kapsayan hava fotoğrafları kullanılmıștır. Kentsel alan kullanımlarını örnekleyecek düzeyde seçilen çalıșma alanı, kontrollü ve obje tabanlı sınıflandırma tekniği ile sınıflandırılarak, sınıflandırma sonuçları karșıaștırmalı olarak değerlendirilmiștir. Doğruluk analizi sonuçlarına göre, kontrollü sınıflandırma için hesaplanan ortalama doğruluk değeri \%82.79, obje tabanlı sınıflandırma için hesaplanan ortalama doğruluk değeri \%92.52 olarak elde edilmiștir.

Anahtar Kelimeler: piksel tabanlı sınıflandırma, obje tabanlı sınıflandırma, kentsel alan kullanımları

\section{The Comparison of Pixel and Object-based Classification for Land Use/Land Cover Mapping}

\begin{abstract}
The classification of high resolution satellite images enable planners and researchers to classify land use/land cover (LULC), which are important in terms of carrying out the planning applications both at city and landscape scale. For conducting different landscape analysis, LULC plays a significant role for numerous applications, such as urban growth analysis, deforestation, etc. Urban atlases provided by European initiatives, Coordination of Information on the Environment (CORINE) and various thematic maps are based on the classification of high resolution satellite images. As a current method, object-based classification is also used effectively in remote sensing researches. The materials of this study are Worldview ortoready pansharpened satellite image with a local resolution of $0.5 \mathrm{~m}$ environs the urban settlement of Aydin dated 2013, and the satellite images belong to the same year acquired from Google Earth Pro software. The research area representing urban green space, barren land, road, building, agricultural field, and shadow was chosen to classify urban LULC by supervised classification and object based classification in a comparative way. The results of the accuracy analysis demonstrate that the object-based classifier achieved a high overall accuracy (92.52\%), whereas the most commonly used decision rule, namely maximum likelihood classifier, produced a lower overall accuracy $(82.79 \%)$. This research shows that the object-based classifier is a significantly better approach than the classical pixel classifiers.
\end{abstract}

Keywords: supervised classification, object based classification, land use/land cover

\section{GiRiș}

Avrupa Çevre Ajansı (AÇA)'nın belirlediği kriterler ve sınıflandırma sistemi doğrultusunda AÇA'ya üye tüm ülkelerde, arazideki çevresel değișimlerin belirlenmesi, doğal kaynakların rasyonel biçimde yönetilmesi ve çevre ile ilgili politikaların olușturulması amaçlarına yönelik olarak, aynı temel verilerin toplanması ve standart bir veri tabanının olușturulmasına yönelik çalıșmalar yürütmektedir. CORINE (Coordination of Information on the Environment-Çevresel Bilginin Koordinasyonu) sınıflarına göre alansal değișimin izlenmesinde olușturulan veri tabanı, üçüncü düzeyde analiz yapmak için yetersizdir. Örnek olarak, 1990 yılına ait veri seti incelenmiș ve "kentsel yeșil alanlar" sınıfının alansal miktarının yer gerçeğine oranla çok sınırlı olduğu gözlemlenmiștir. Sınıflandırma doğruluğu \%85'in altında olarak belirtilmiș olmasına rağmen ileri düzeyde bir değișim analizi yapmak mümkün değildir. Bu nedenle kentlere ait kentsel alan kullanım sınıflarının olușturulmasında güncel görüntü tekniklerinin kullanılması, yapılacak çevresel analizlerin de doğruluğu açısından önemlidir (Camps-Valls ve ark., 2014; Li ve ark., 2017; Maggiori ve ark., 2017).

Uydu görüntüleri yardımıyla kentsel alan kullanımlarının sınıflandırılmasında farklı algoritmalara (obje tabanlı en yakın komșuluk, destek vektör makineleri, karar ağacı analizleri gibi) dayanan yöntemler kullanılmaktadır (Cristianini ve Shawe-Taylor, 2000; Melgani ve Bruzzone, 2004; Tzotsos ve Argialas, 2008; Ustuner ve ark., 2017). Çözünürlüğü 2.5-4 metre arasındaki lkonos veya Quickbird gibi yüksek çözünürlüklü görüntüler, bugüne kadar kent paternini tüm detayları ile gösteren haritaların üretilmesini sağlamıștır. Geleneksel sınıflandırma yöntemleri, görüntüdeki spektral bilgi veya renklere dayanan piksel yaklașımlarını (Bayes teoremi veya yapay sinir ağları) benimsemektedir (Schowengerdt, 2012). Ancak bu sınıflandırmada, üretilen haritalardaki sınıfların doğruluğu sınırlıdır. Bir diğer ifadeyle,

Sorumlu Yazar: derya.yazgi@adu.edu.tr

Geliș Tarihi: 15 Mayıs 2018

Kabul Tarihi: 7 Aralık 2018 
uydu görüntülerinin mekânsal çözünürlüğünün artması ile içerdikleri zengin bilgi içerikleri, piksel tabanlı sınıflandırmada tutarsız sonuçlar gösterebilmektedir. Bu nedenle günümüzde, piksellerin yanında anlamlı nesneler ve karșılıklı ilișkilerle görüntünün sınıflandırılmasını sağlayan obje tabanlı sınıflandırma tekniği kullanılmaktadır (Blaschke ve ark., 2004; Blaschke, 2010; Dingle Robertson ve King, 20II; Whiteside ve ark., 20II; Duro ve ark., 20I2). Renk, doku, sıklık ve komșuluk gibi belirli özellikleri referans alan obje tabanlı sınıflandırma, benzer spektral özelliklere sahip piksellerin gruplandırılarak görüntüde anlamlı nesnelerin olușturulması temeline dayanmaktadır.

Bu çalıșmanın amacı, Aydın kent merkezinde, kentsel alan kullanımlarını örnekleyecek düzeyde seçilen test alanını, kontrollü ve obje tabanlı sınıflandırma tekniği ile sınıflandırılarak, sınıflandırma sonuçları karșılaștırmalı olarak değerlendirmektir. Obje tabanlı sınıflandırmada, eCognition
Developer 9.0 yazılımı kullanılarak segmentasyon așamasında çoklu çözünürlük algoritmasından (Multiresolution Segmentation) faydalanılmıștır. Segmentasyon așamasında, ölçek değerinin doğru belirlenebilmesi için çok sayıda deneme yapılmıș ve sınıflandırmanın bașarısı kontrol edilmiștir.

\section{MATERYAL ve YÖNTEM}

$\mathrm{Bu}$ çalıșmanın materyalini, 2013 yılına ait Aydın kentsel yerleșim merkezi sınırındaki $0.5 \mathrm{~m}$ yersel çözünürlüğe sahip Worldview Ortoready pansharpened uydu görüntüsü ve görüntünün yorumlanmasında Google Earth Pro yazılımının geçmiș görüntüleri arasında aynı yılı kapsayan hava fotoğrafları olușturmaktadır. Çalıșma alanı, UTM koordinat sistemine göre $37^{\circ} 49^{\prime}-37^{\circ} 5 \mathrm{I}$ ' $\mathrm{K}$ ve $27^{\circ} 48^{\prime}-27^{\circ} 50^{\prime} \mathrm{D}$ arasında yer almaktadır ve yaklașık $\mathrm{I} .500$ hektar alan kaplamaktadır (Șekil I).

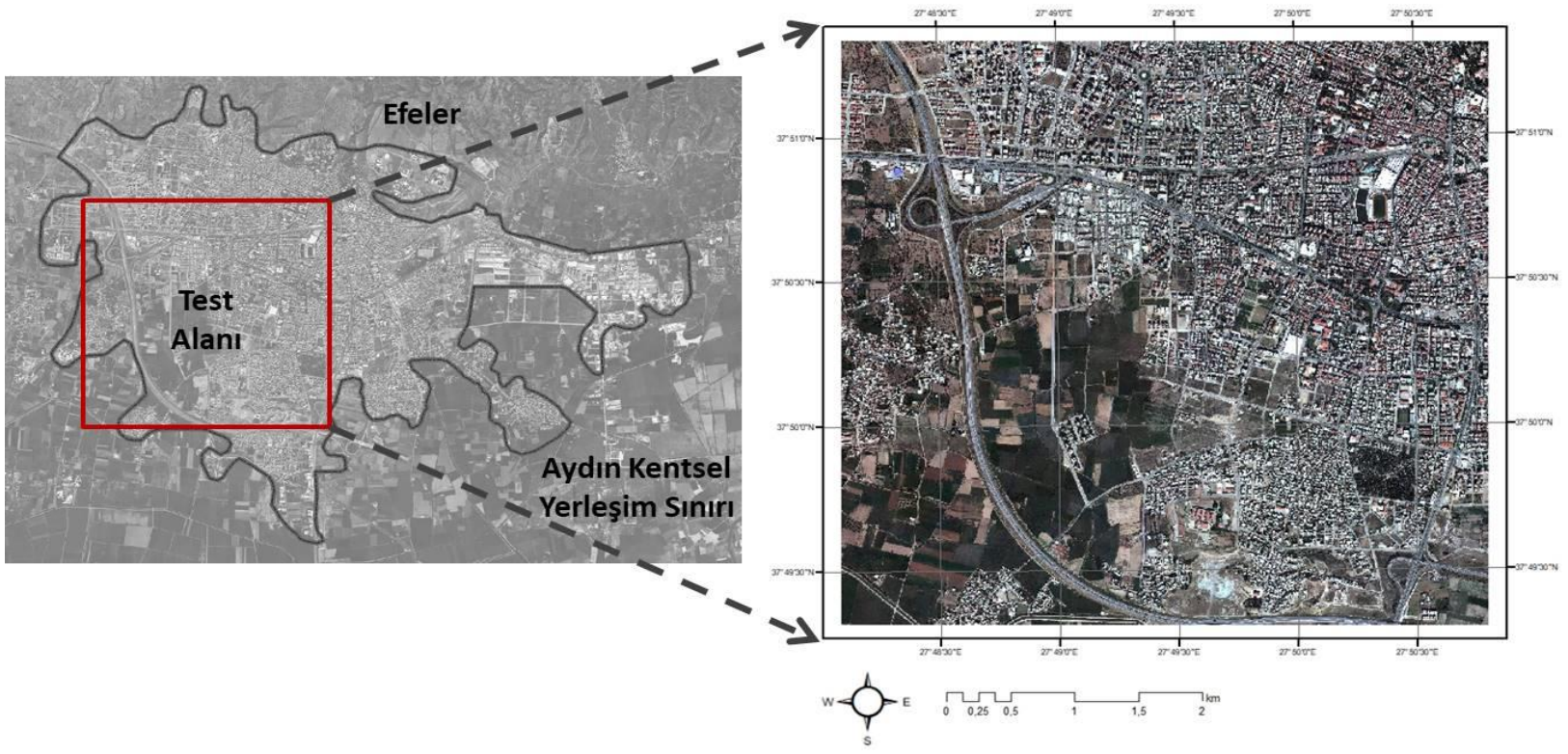

Șekil I. Çalıșma alanı

Kentsel alan kullanımlarını örnekleyecek düzeyde seçilen test alanında; konut, yol, tarım alanı, kentsel yeșil alanlar ve diğer açık alanlar olmak üzere toplam 5 sınıf bulunmaktadır. Piksel tabanlı sınıflandırma için ArcMap 10.5 yazılımı, obje tabanlı sınıflandırma için ise eCognition Developer 9.0 yazılımı kullanılmıștır. Segmentasyon așamasında çoklu çözünürlük algoritmasından (Multiresolution Segmentation) faydalanılmıștır. Çalıșmanın yöntem akıș șeması Șekil 2'de sunulmuștur.

Yapılan ișlemlerin doğruluğunu test etmek amacıyla, piksel değerlerinin referans olarak kabul edilen haritalar veya araziye ait yer gerçekleri ile istatistiksel olarak karșılaștırılması yapılmaktadır. Hata ölçüsünü belirlemek için hata matrisi kullanılmaktadır. Hata matrislerinden elde 44 edilen sınıflar arası doğrulukların belirlenmesinde, Kappa (K) katsayısı kullanılmaktadır (Cohen, 1960; Campbell, 1996).

$$
k=\frac{N \sum_{i=1}^{r} x_{i i}-\sum_{i=1}^{r}\left(x_{i+} * x_{+i}\right)}{N^{2}-\sum_{i=1}^{r}\left(x_{i+} * x_{+i}\right)}
$$

$r$ : Hata matrisindeki satırların sayısı

xii : Satır i ve sütün i'deki gözlemlerin sayısı

xti : Satır i'deki toplam gözlem

xit : Sütün i'deki toplam gözlem

$\mathrm{N}$ : Matriste içerilen toplam gözlem sayısı 


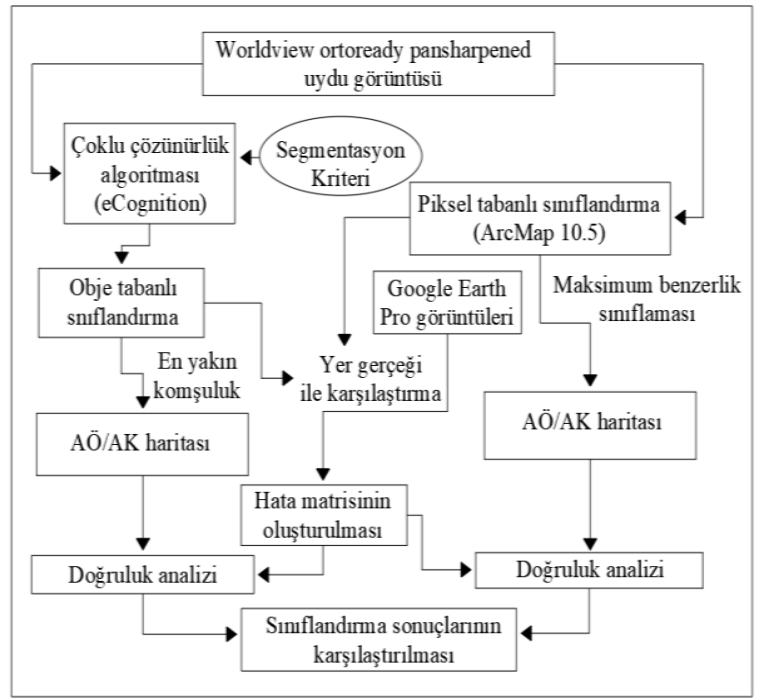

Șekil 2. Yöntem akıș șeması (Rahman ve Saha, 2008'den değiștirilerek)
Doğruluk analizinde genel doğruluk, tüm doğru atanmış piksel sayısı/tüm pikseller sayısını; kullanıcı doğruluğu, bir sınıfa ait doğru sınıflandırılan piksel sayısı/o sınıftaki toplam piksel sayısını; üretici doğruluğu ise bir sınıfa ait doğru sınıflandırılan piksel sayısı/bir sınıftaki olması gereken gerçek piksel sayısını ifade etmektedir (Congalton, 199I; Jensen, 2005).

\section{BULGULAR ve TARTIȘMA}

Kontrollü sınıflandırma yöntemine göre, sınıflandırmanın kullanıcı tarafından belirlenmesinde referans alınabilecek hava fotoğrafları, çeșitli haritalar ya da arazi sörveyleri kullanılabilir (Mather, 1987). Bu yöntemin uygulanmasında, 2013 yılına ait hava fotoğraflarından yararlanılarak her bir sınıflandırma alanı için 100 adet test alanı seçilmiștir. Maksimum benzerlik algoritması ile kullanılarak olușturulan kontrollü sınıflandırılmıș görüntü Șekil 3'de sunulmuștur.

Sınıflandırma sonucunda tarım alanları ile kentsel yeșil alanların benzer spektral özelliklere sahip olması nedeniyle karıșmıș olduğu görülmektedir. Aynı durum, yol ile açık alanlar sınıfı için de geçerlidir.

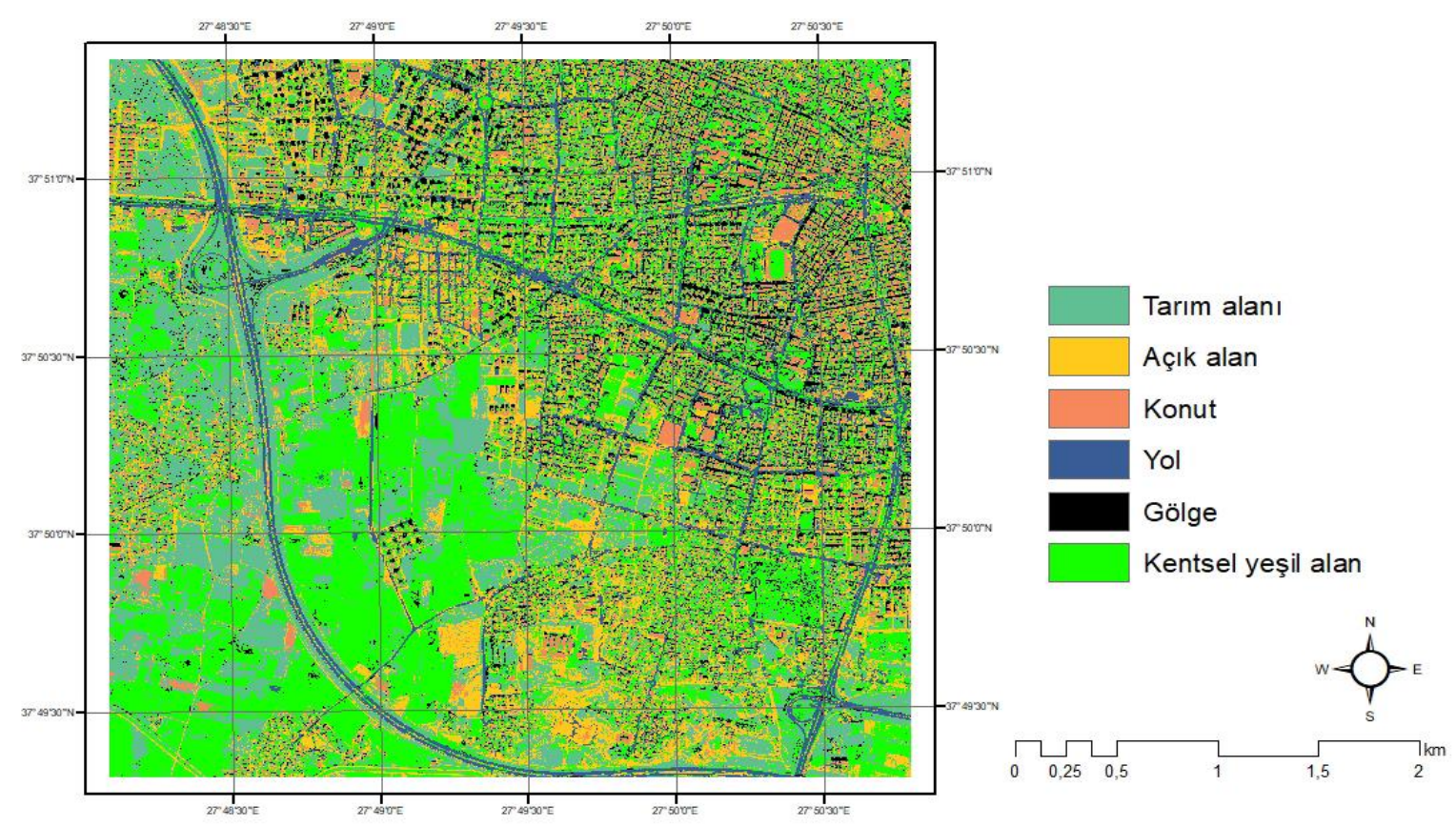

Șekil 3. Kontrollü sınfflandırma sonucu

Obje tabanlı sınıflandırmanın ilk așaması segmentasyondur. Segmentasyon, benzer spektral özelliklere sahip piksellerin gruplandırılarak, mekânsal karakteri farklı objelere bölünmesi ișlemidir (Ryherd ve Woodcock, 1996; Baatz ve ark., 2004; Kalkan, 20II). Komșu piksellerin bir araya getirilmesi ile belirli poligonların veya görüntü nesnelerinin olușturulması için bu așamada çok sayıda test yapılmıștır (Șekil 4).
Çoklu çözünürlük algoritmasının (Multiresolution Segmentation) uygulanmasında, șekil, yoğunluk ve ölçek parametrelerinin doğru belirlenmesi önemlidir (Benz ve ark, 2004). Yapılan testler sonucunda, sınıflandırma ölçeği olarak 50 , șekil ve yoğunluk parametreleri için sırasıyla 0.1 ve 0.5 değerleri kullanıımıștır. Sınıflandırma sonucu Șekil 5'de sunulmuștur. 

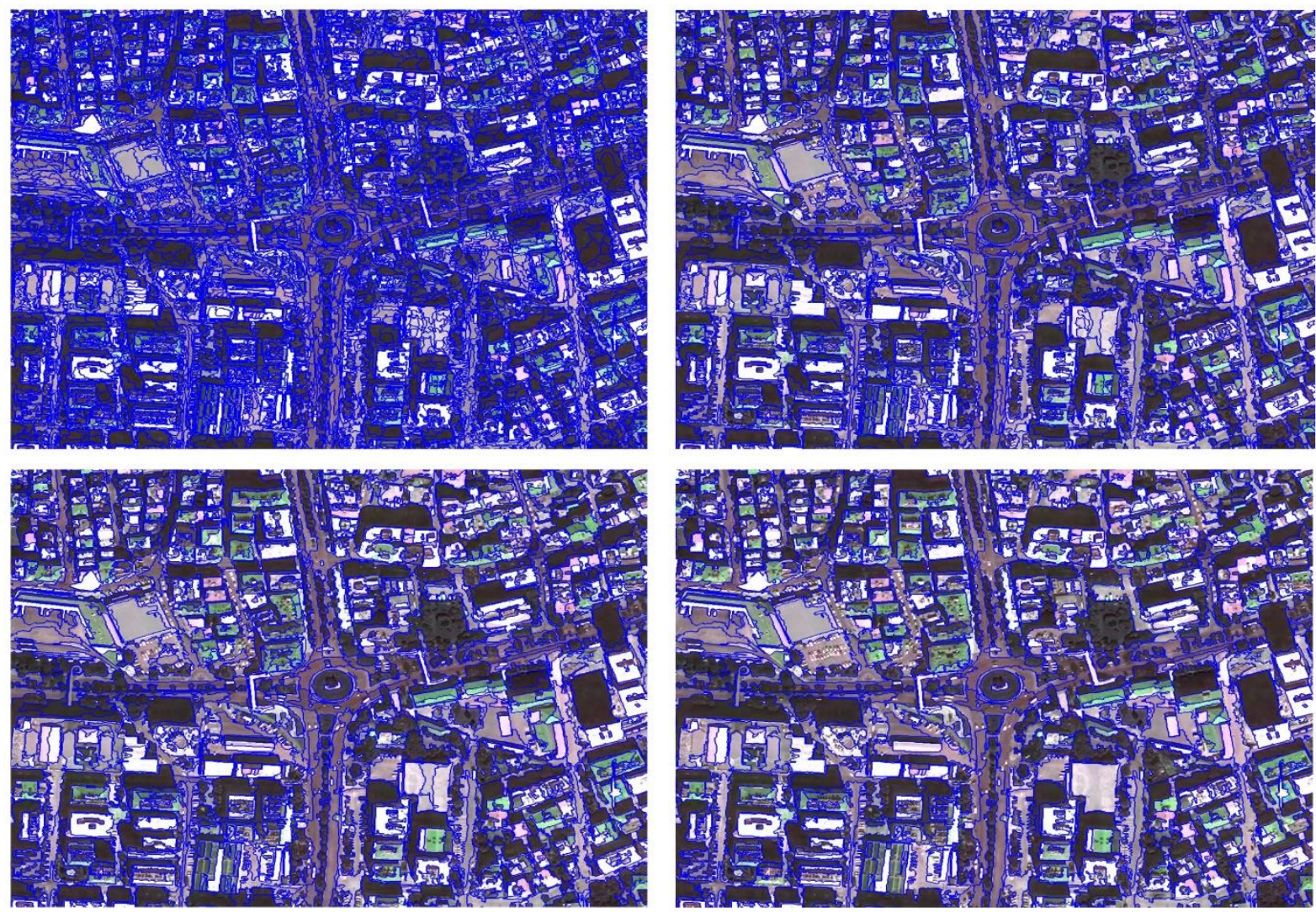

Șekil 4. Örnek bir test alanına ait segmentasyon ölçek değerleri: 20 (sol üst), 50 (sağ üst), 70 (sol alt), 100 (sağ alt). (Mavi renkteki çizgiler objelerin ayrılma sınırlarını göstermektedir)

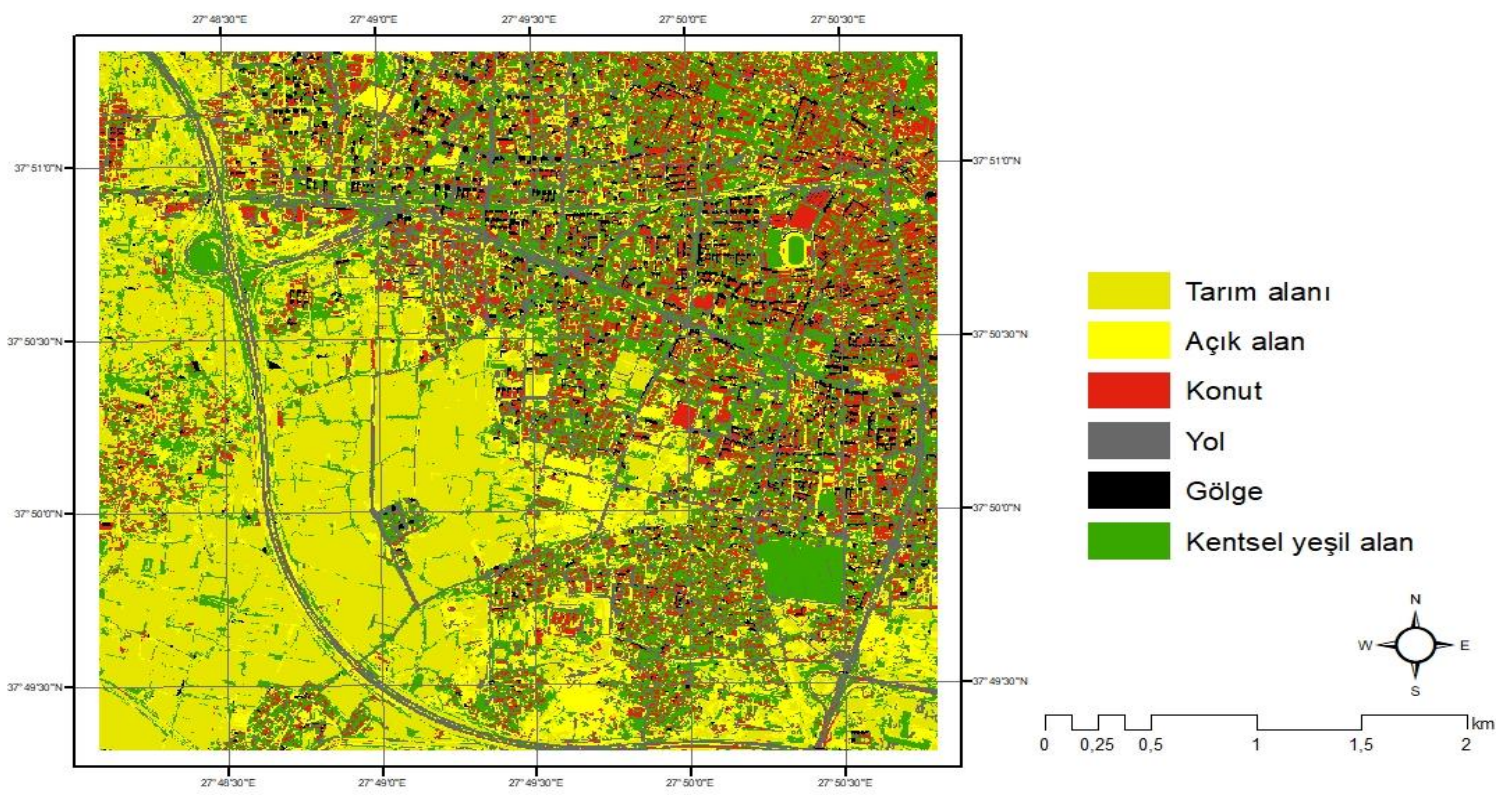

Șekil 5. Obje tabanlı sınıflandırma yöntemi ile sınıflandırılmıș görüntü 
Doğruluk analizinin yapılması amacıyla sınıflanmıș görüntü üzerinden toplam 198 kontrol noktası belirlenmiștir. Bu çalıșma kapsamında, kontrollü sınıflandırma ve obje tabanlı sınıflandırma sonucu olușturulan görüntülere ait doğruluk analizi sonuçları Çizelge I'de sunulmuștur.

Çizelge I. Doğruluk analizi sonuçları

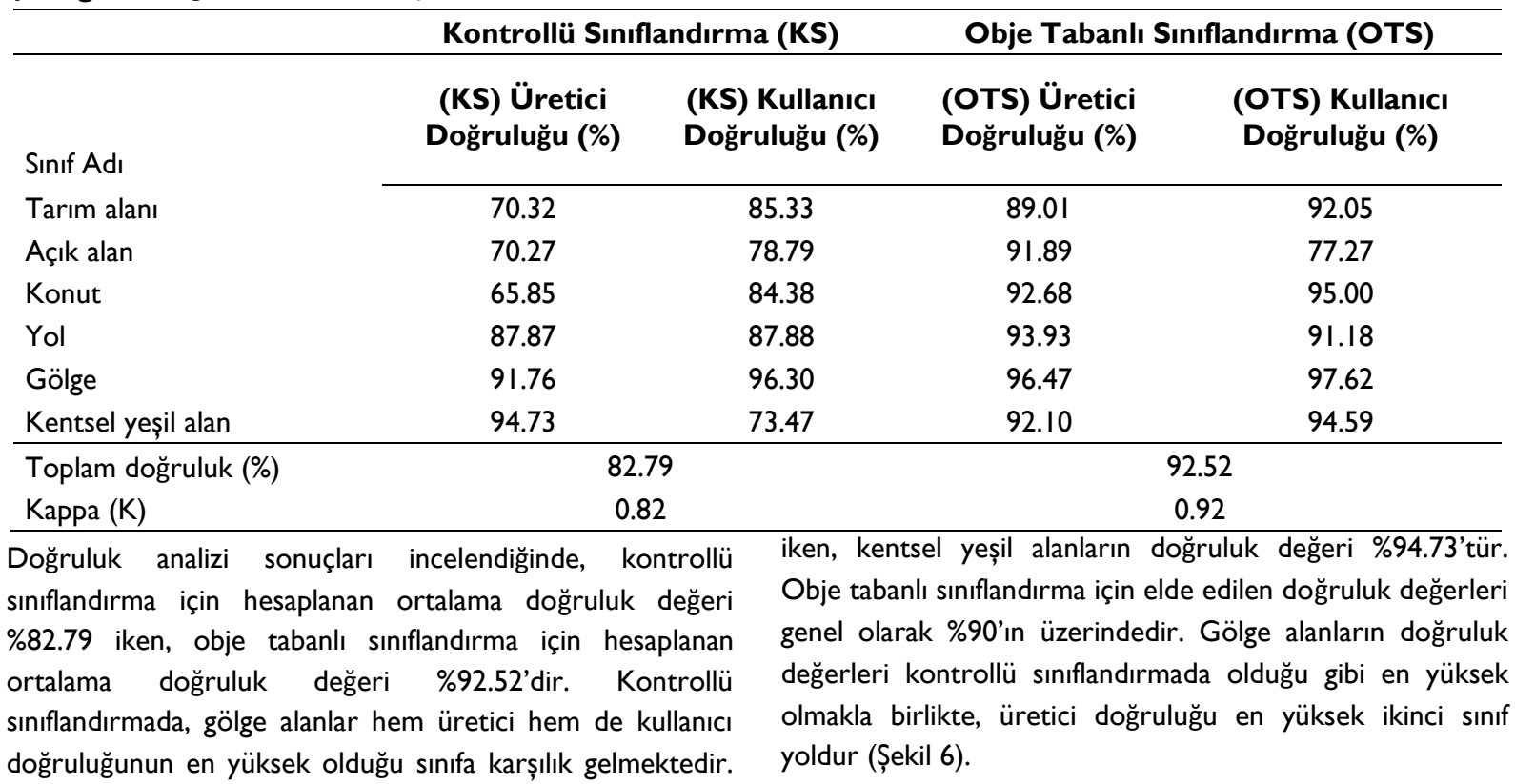

Tarım alanı ve açık alanların üretici doğruluğu yaklașık \%70

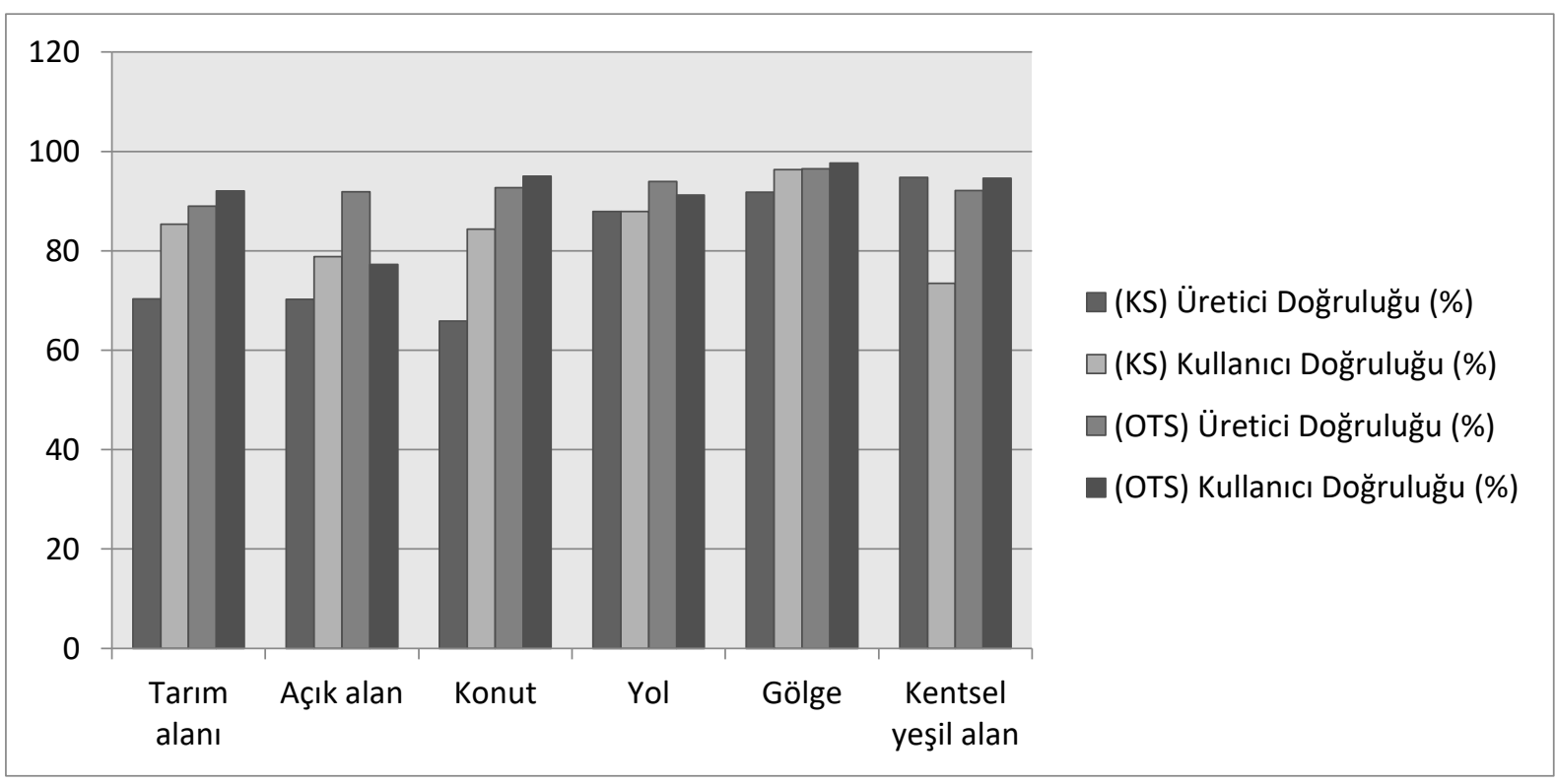

Șekil 6. Her iki sınıflandırmaya ait üretici ve kullanıcı doğruluğu değerleri (\%)

\section{SONUÇ}

Yüksek çözünürlüklü uydu görüntülerinin sınıflandırılmasıyla olușturulan arazi örtüsü-arazi kullanımı (AÖ/AK) envanterleri, hem kent ölçeğinde hem de peyzaj ölçeğindeki planlama uygulamalarının yürütülmesi açısından önemlidir. Doğru sınıflandırma tekniklerinin kullanılması, özellikle çevresel izleme ve değișim çalıșmalarının yürütülmesinde etkilidir (Chen ve ark., 2012; Hussain ve ark. 20I3; Yu ve ark., 2016). Avrupa'da alan kullanım planlaması kapsamında hazırlanan kent atlasları, peyzaj ölçeğindeki Natura 2000 ve CORINE AÖ veri setlerinin kombinasyonuna dayanan haritalar, uydu görüntülerinin yüksek doğrulukla sınıflandırılması ile olușturulmaktadır. 
Avrupa Çevre Ajansı'na üye tüm ülkelerde, erișilebilir bir CORINE veri tabanı olușturulmuștur. Türkiye'de kentlere ait arazi kullanımı sınıflarını CORINE'in tüm düzeylerinde mevcut gösteren veri tabanında özellikle ikinci ve üçüncü düzey sınıflarda hatalar olduğu tespit edilmiștir. Kentlere ait arazi kullanımı sınıflarının belirlenmesinde, yüksek doğrulukla sınıflandırılmıș verinin kullanılması, yapılacak peyzaj analizi çalıșmalarının doğruluğu açısından da büyük önem tașımaktadır.

$\mathrm{Bu}$ çalıșma kapsamında yapılan doğruluk analizi sonuçları incelendiğinde, kontrollü sınıflandırma için $\mathrm{K}$ değeri 0.82 iken, obje tabanlı sınıflandırma için hesaplanan $K$ değeri 0.92 'dir. Kontrollü sınıflandırma ve obje tabanlı sınıflandırma sonucunda, obje tabanlı sınıflandırmanın doğruluğunun daha yüksek seviyede olduğu görülmüștür. Gölge alanların sınıflandırma doğruluğu her iki sınıflandırmada da çok yüksek çıksa da, bu alanlar sınıflandırma açısından sorun yaratmaktadır (Zhou ve ark., 2009; Zhu ve Woodcock, 2012). Farklı algoritmalar geliștirilerek, bu alanların sınıflandırmadan otomatik olarak çıkarılmasına yönelik çalıșmaların yapılması ileride yapılacak diğer çalıșmalar için de katkı sağlayacaktır.

Güncel olarak yapılan çalıșmaların çoğunda, yüksek mekânsal çözünürlük ve yüksek spektral çözünürlüğe sahip görüntüler için arazi kullanımının belirlenmesinde obje tabanlı yaklașımın yüksek doğrulukta sonuçlar verdiği gözlemlenmiștir (Plat ve Rapoza, 2008; Kalkan ve Maktav, 2010; Tehrany ve ark., 2013; Yu ve ark., 2016). Ayrıca, bu sınıflandırma ile yapılan hatalar ya da hatalı sınıf atamaların hızlı bir șekilde düzeltilebileceği belirtilmiștir.

Yüksek doğruluk gösteren AÖ/AK'nın sınıflandırılması; kentsel planlama çalıșmalarında, peyzaj analizlerinde, çevresel değișim ve izleme çalıșmalarında altlık veri olarak kullanılmaktadır. Bu nedenle, uzaktan algılama çalıșmalarında tercih edilen sınıflandırma yöntemleri arasında obje tabanlı sınıflandırma genellikle yüksek doğrulukta sonuçlar ürettiği için tercih edilebilir.

\section{KAYNAKLAR}

Baatz $M$, Benz $U$, Dehghani $S$, Heynen $M$, Höltje $A$, Hofmann P, Lingenfelder I, Mimler M, Sohlbach, M, Weber M, Willhauck G (2004) eCognition Professional User Guide, Version 4.0. Definiens Imaging $\mathrm{GmbH}$. München, Germany: Definiens.

Benz UC, Hofmann P, Willhauck G, Lingenfelder I, Heyen M (2004) Multi-resolution, Object-oriented Fuzzy Analysis of Remote Sensing Data for GIS-ready Information. ISPRS Journal of Photogrammetry \& Remote Sensing 58: 239-58.

Blaschke T (2010) Object based image analysis for remote sensing. ISPRS Journal of Photogrammetry and Remote Sensing, 65(I): 2-16.
Blaschke T, Burnett C, Pekkarinen A (2004) Image segmentation methods for object-based analysis and classification. In Remote sensing image analysis: Including the spatial domain (pp. 21।-236). Springer, Dordrecht.

Campbell JB (1996) Introduction to Remote Sensing. Guilford Press, New York.

Camps-Valls G, Tuia D, Bruzzone L, Benediktsson JA (2014) Advances in hyperspectral image classification: Earth monitoring with statistical learning methods. IEEE Signal Processing Magazine, 3 I (I): 45-54.

Chen G, Hay GJ, Carvalho LM, Wulder MA (20I2) Objectbased change detection. International Journal of Remote Sensing, 33(14): 4434-4457.

Cohen J (1960) A Coefficient of Agreement for Nominal Scales. Educational and Psychological Measurement, 20 (I): 37-46.

Congalton RG (1991) A review of assessing the accuracy of classifications of remotely sensed data. Remote Sensing of Environment, 37(1): 35-46.

Cristianini N, Shawe-Taylor J (2000) An introduction to support vector machines and other kernel-based learning methods. Cambridge University Press, 187s.

Dingle Robertson L, King DJ (201I) Comparison of pixeland object-based classification in land cover change mapping. International Journal of Remote Sensing, 32(6): I505-I529.

Duro DC, Franklin SE, Dubé MG (20I2) A comparison of pixel-based and object-based image analysis with selected machine learning algorithms for the classification of agricultural landscapes using SPOT-5 HRG imagery. Remote Sensing of Environment, II8: 259-272.

Hussain M, Chen D, Cheng A, Wei H, Stanley D (2013) Change detection from remotely sensed images: From pixel-based to object-based approaches. ISPRS Journal of Photogrammetry and Remote Sensing, 80: 91-106.

Jensen JR (2005) Introductory Digital Image Processing: A Remote Sensing Perspective. Pearson Prentice Hall, Upper Saddle River, NJ.

Kalkan K (20II) Kentsel Gelișim için Potansiyel Açık Alanların Belirlenmesinde Nesne Tabanlı Sınıflandırma Yöntemi ile Transfer Edilebilir Kural Dizisi Olușturulması. Yüksek Lisans Tezi, İstanbul Teknik Üniversitesi Fen Bilimleri Enstitüsü, İstanbul.

Kalkan K, Maktav D (2010) Nesne Tabanlı ve Piksel Tabanlı Sınıflandırma Yöntemlerinin Karșılaștırılması (IKONOS Örneği). III. Uzaktan Algılama ve Coğrafi Bilgi Sistemleri Sempozyumu, II - I3 Ekim 2010, Gebze - Kocaeli.

Li W, Wu G, Zhang F, Du Q (2017) Hyperspectral image classification using deep pixel-pair features. IEEE Transactions on Geoscience and Remote Sensing, 55(2): 844-853. 
Maggiori E, Tarabalka Y, Charpiat G, Alliez P (2017) Convolutional neural networks for large-scale remotesensing image classification. IEEE Transactions on Geoscience and Remote Sensing, 55(2): 645-657.

Mather P M (1987) Computer Processing of Remotely Sensed Images: An Introduction, John Wiley \& Sons Ltd., 360s.

Melgani F, Bruzzone L (2004) Classification of hyperspectral remote sensing images with support vector machines. IEEE Transactions on Geoscience and Remote Sensing, 42(8): $1778-1790$.

Platt R V, Rapoza L (2008) An Evaluation of an ObjectOriented Paradigm for Land Use/Land Cover Classification. The Professional Geographer, 60 (I): 87 100.

Rahman MR, Saha SK (2008) Multi-Resolution Segmentation for Object-based Classification and Accuracy Assessment of Land Use/Land Cover Classification Using Remotely Sensed Data. Journal of the Indian Society of Remote Sensing, 36(2): 189-201.

Ryherd S, Woodcock C (1996) Combining Spectral and Texture Data in the Segmentation of Remotely Sensed Images. Photogrammetric Engineering and Remote Sensing, 62: 181-194.

Schowengerdt, RA (20I2) Techniques for image processing and classifications in remote sensing. Academic Press, 249s.

Tehrany MS, Pradhan B, Jebuv MN (2014) A comparative assessment between object and pixel-based
GÜLÇIN D classification approaches for land use/land cover mapping using SPOT 5 imagery. Geocarto International, 29(4): $351-369$.

Tzotsos A, Argialas D (2008) Support vector machine classification for object-based image analysis. In ObjectBased Image Analysis (pp. 663-677). Springer, Berlin, Heidelberg.

Ustuner M, Sanli FB, Dixon B (2015) Application of support vector machines for landuse classification using highresolution RapidEye images: a sensitivity analysis. European Journal of Remote Sensing, 48(I): 403-422.

Whiteside TG, Boggs GS, Maier SW (20II) Comparing object-based and pixel-based classifications for mapping savannas. International Journal of Applied Earth Observation and Geoinformation, 13(6): 884-893.

Yu W, Zhou W, Qian Y, Yan J (2016) A new approach for land cover classification and change analysis: Integrating backdating and an object-based method. Remote Sensing of Environment, 177: 37-47.

Zhou W, Huang, G, Troy A, Cadenasso ML (2009) Objectbased land cover classification of shaded areas in high spatial resolution imagery of urban areas: A comparison study. Remote Sensing of Environment, II3(8): 17691777.

Zhu Z, Woodcock CE (20I2) Object-based cloud and cloud shadow detection in Landsat imagery. Remote Sensing of Environment, I 18: 83-94. 
